\title{
Reinfection tuberculosis: two cases in the family of a patient with drug-resistant disease
}

\author{
P ORMEROD AND C SKINNER
}

\author{
From East Birmingham Hospital, Birmingham
}

ABSTRACT A 42-year-old housewife died of drug-resistant pulmonary tuberculosis. Two sons had earlier completed a course of treatment for drug-sensitive disease. Six months after her deather both sons developed sputum-positive tuberculosis with a drug resistance pattern identical to that of their mother during her last year of life, and including resistance to drugs which neither sonhad received. In both cases immunocompetence to tuberculin was shown so that reinfection aroseñ purely as a result of heavy exposure.

Recurrence of active tuberculosis is usually the result of reactivation of apparently healed disease, and the role of exogenous reinfection is thought to be small. ${ }^{2}$ We know of only two single case reports in which reinfection tuberculosis is well documented. ${ }^{34}$ We therefore wish to report a family in which two brothers developed a recurrence of pulmonary tuberculosis as a result of reinfection by their mother who had progressive, ultimately fatal, drug-resistant disease.

\section{Case reports}

CASE 1

A 16-year-old Caucasian youth was admitted to hospital in September 1971 with a nine-month history of productive cough, occasional haemoptysis, weight loss $(7 \mathrm{~kg}$ ), and vague left-sided chest pain. There were crackles in the left lower chest. A chest radiograph showed soft, bilateral, midzone shadowing, more pronounced on the left. Heaf test was strongly positive $(15 \mathrm{~mm}$ of induration); he had not had BCG vaccination.

Sputum smears showed acid-fast bacilli, and cultures of several specimens yielded a growth of Mycobacterium tuberculosis fully sensitive to streptomycin, isoniazid, and PAS. He was given streptomycin $0.75 \mathrm{~g}$ daily and Pasinah D (PAS $6 \mathrm{~g}$, isoniazid $150 \mathrm{mg}$ ) twice daily for three months as an inpatient, and was then discharged on Pasinah D twice daily.

There was progressive clinical and radiographic improvement, and sputum conversion was attained

Address for reprint requests: Dr C Skinner, East Birmingham Hospital, 45 Bordesley Green East, Bordesley Green, Birmingham B9 5ST. after four months. Chemotherapy was given foro 20 months, although there was some doubt as to whether he took his drugs regularly during the last six months of treatment. He was seen at inter vals until May 1977, and there was no clinica or radiographic deterioration.

He presented again in May 1978 with a six $\cong$ month history of cough and vague ill health. $A \overrightarrow{\overrightarrow{0}}$ chest radiograph showed new soft shadowing in the left upper lobe with early cavitation. Sputum was smear-positive, and cultures of several speci mens were positive after two weeks, yielding a growth of $M$ tuberculosis with drug sensitivities as shown in the table. These sensitivities were confirmed by the Mycobacterial Reference Lab3 oratory in Cardiff.

Mantoux test (1 TU) was positive $(20 \mathrm{~mm}$ in duration). Serum IgG and IgA were normal while IgM was raised at $3 \cdot 10 \mathrm{~g} / 1$. In vitro evaluation of cellular immunity including lymphocyte transfor $\frac{\text { o }}{2}$ mation to PPD, T and B lymphocyte rosette for mation, lymphocyte surface immunofluorescence ${ }^{N}$ and inhibition of leucocyte migration by BCG gavê normal results.

At the time of writing he is doing well on $\mathfrak{a}^{N}$ regimen of isoniazid, pyrazinamide, prothionamide? and cycloserine.

CASE 2

A younger brother (aged $13 \mathrm{yr}$ ) of the first patien 5 was seen as a contact in October 1971. A chest而 radiograph was normal, but Heaf test was positive (grade 4). Chemoprophylaxis with Inapasade (PASO $6 \mathrm{~g}$, isoniazid $150 \mathrm{mg}$ ) twice daily was begun, buर dosage was halved after one month because of 
Table Sputum status, ${ }^{*}$ drug treatment, and drug sensitivity/resistance $\dagger$

\begin{tabular}{|c|c|c|c|c|c|c|c|c|c|}
\hline Case & & 1971 & 1972 & 1973 & 1974 & 1975 & 1976 & 1977 & 1978 \\
\hline 1 & $\begin{array}{l}\text { Sputum } \\
\text { Sensitivity } \\
\text { Resistance } \\
\text { Treatment }\end{array}$ & $\begin{array}{l}++ \\
\text { SHP } \\
\text { SHP }\end{array}$ & HP & HP & - & & & & $\begin{array}{l}++ \\
\text { HPZEtTCy } \\
\text { SREC }\end{array}$ \\
\hline 2 & $\begin{array}{l}\text { Sputum } \\
\text { Sensitivity } \\
\text { Resistance } \\
\text { Treatment }\end{array}$ & HP & HP & & $\begin{array}{l}\stackrel{+}{\text { SHP }} \\
\text { SHP }\end{array}$ & $\begin{array}{l}- \\
\text { SH }\end{array}$ & $\begin{array}{l}- \\
\text { SH }\end{array}$ & & $\begin{array}{l}++ \\
\text { HPZEtTCy } \\
\text { SREC }\end{array}$ \\
\hline 3 & $\begin{array}{l}\text { Sputum } \\
\text { Sensitivity } \\
\text { Resistance }\end{array}$ & & & & $\begin{array}{l}+ \\
\text { SHP }\end{array}$ & $\begin{array}{l}+ \\
\text { SPR } \\
\text { HE }\end{array}$ & + & $\frac{++}{\text { TCy }}$ & \\
\hline & Treatment & & & & $\underset{\rightarrow \text { SHE }}{\text { SHP }}$ & $\underset{\rightarrow \mathrm{SH}}{\mathrm{HE}}$ & CR & ZPrCy & \\
\hline
\end{tabular}

$*++=$ Smear and culture positive $+=$ Smear negative, culture positive; $-=$ Smear and culture negative.

$\begin{array}{llll}\dagger & \mathbf{R}=\text { rifampicin } & \text { Et=ethionamide } & \text { streptomycin } \\ \mathbf{H}=\text { isoniazid } & \mathbf{E}=\text { ethambutol } & \text { Pr=prothionamide } & \text { Cy=cycloserine } \\ \mathbf{P}=\text { PAS } & \mathbf{Z}=\text { pyrazinamide } & \text { C=capreomycin } & \end{array}$

nausea. Treatment was continued for 12 months.

He presented again in March 1974 with new soft shadowing in the right upper lobe on chest radiograph. Several sputum cultures were positive, yielding a growth of $M$ tuberculosis fully sensitive to streptomycin, isoniazid, and PAS. He received streptomycin $0.75 \mathrm{~g}$ daily and Pasinah 302 (PAS $6 \mathrm{~g}$, isoniazid $150 \mathrm{mg}$ ) twice daily for three months as an inpatient. Sputum conversion was attained in two months. He was then discharged on Pasinah 302 twice daily.

Four months after discharge there was some radiological improvement but he admitted to having stopped taking the treatment one month previously. He refused readmission. Supervised twice-weekly streptomycin $1.0 \mathrm{~g}$ and isoniazid $800 \mathrm{mg}$ was given for 18 months until June 1976, with virtually complete radiographic clearing. He was seen at intervals until January 1978 and had no clinical or radiographic deterioration.

He had chest radiography again in July 1978 because of the new disease in his elder brother. There was new soft shadowing at the left apex. $\mathrm{He}$ was admitted to hospital. Sputum was smearpositive and cultures of several specimens were positive after three weeks, yielding a growth of $M$ tuberculosis with drug sensitivities as shown in the table. These sensitivities were confirmed by the Mycobacterial Reference Laboratory in Cardiff.

Tuberculin test (1 TU) was positive $(40 \mathrm{~mm}$ induration). Serum immunoglobulins were normal. In vitro lymphocyte transformation to PPD and inhibition of leucocyte migration by BCG were also normal.

$\mathrm{He}$ is now doing well on a regimen of isoniazid, pyrazinamide, prothionamide, and cycloserine.
CASE 3

The mother, aged $37 \mathrm{yr}$, of these two patients was seen as a contact of the first patient in 1971. She was asymptomatic. A chest radiograph showed scattered localised calcification mainly in the right lower zone. Annual chest films to April 1974 showed no change. In September 1974 she was seen because of weight loss and nausea for one month. A chest radiograph showed new soft shadowing at the right apex, with no change in the previously noted calcification. She was admitted to hospital.

Mantoux test (10 TU) was positive, sputum culture yielded a growth of $M$ tuberculosis fully sensitive to streptomycin, isoniazid, and PAS. She was given streptomycin $0.75 \mathrm{~g}$ daily and Pasinah D twice daily. After one month PAS was stopped because of nausea, and ethambutol $(15 \mathrm{mg} / \mathrm{kg})$ substituted. After 46 days streptomycin was stopped, and she was discharged on isoniazid and ethambutol (Mynah 200), three tablets daily. Sputum conversion was attained six weeks after starting treatment.

She defaulted several times and was not seen until four months after discharge. At that time, however, her chest radiograph showed considerable improvement and she was culture-negative. In September 1975 she admitted to very irregular drug taking, and the radiograph showed new shadowing in the right apex and left midzone. She refused hospital admission and was started on twice-weekly supervised streptomycin $1.0 \mathrm{~g}$ and isoniazid $700 \mathrm{mg}$. Sputum at this time was positive on culture with drug sensitivities as shown in the table. By the time isoniazid resistance was reported she had been on the supervised streptomycin/ 
isoniazid regimen for 10 weeks. At this point streptomycin resistance was also assumed, and treatment was stopped.

Sputum was recultured in January 1976 (see table) when chest radiograph showed progressive disease and also early cavitation of the right upper lobe. Daily supervised capreomycin $0.75 \mathrm{~g}$ and rifampicin $450 \mathrm{mg}$ were started. Over the next six months there was no radiological change, and sputum cultures in April and July 1976 were negatime. In October 1976, however, there was radiographic deterioration with a large right apical cavity, and increased shadowing on the right. Sputum was again culture-positive, but drugs were continued until sensitivities were known. These showed resistance to capreomycin and rifampicin (see table), and treatment was stopped in April 1977. From that time she remained chronically smear-positive with these resistant organisms. The sensitivities were confirmed by the Mycobacterial Reference Laboratory in Cardiff, which also reported a mixture of isoniazid-resistant and isoniazid-sensitive organisms. The patient was eventually persuaded to enter hospital in September 1977. A regimen of pyrazinamide, prothionamide, and cycloserine was tried but had to be abandoned because of nausea and epileptiform fits. A right pneumonectomy was, therefore, performed in October 1977. One week later a bronchopleural fistula developed, which was not controlled by thoracoplasty and surgical repair. She went on to develop a discharging thoracotomy wound and bronchopneumonia in the remaining lung, and died six weeks after operation. Histology of the resected lung confirmed fibrocaseous tuberculosis. Necropsy showed only a few calcified tuberculomas and no active disease in the left lung.

\section{Discussion}

There has been contention for many years over the possible role of exogenous reinfection in the pathogenesis of tuberculosis in man. On epidemiological grounds, Stead ${ }^{1}$ concluded that man was as difficult to reinfect as laboratory animals, that chronic or recurrent pulmonary disease was the result of reactivation of the residuum of the primary infection, and that exogenous reinfection could be discounted as a significant factor. Romeyn, ${ }^{2}$ however, reanalvsed the data interpreted by Stead and concluded that in environments of high infectivity exogenous reinfection did play a part. He pointed out that reinfection might act either bv creating new foci of infection or by reactivating old, "silent" foci, perhaps immunologically.
In the individual case, exogenous reinfection $\stackrel{\overrightarrow{\vec{S}}}{\stackrel{\vec{P}}{\rightarrow}}$ can be proved by showing that the organism re- $\bar{C}$ sponsible for the second (or later) clinical episode $\frac{\bar{F}}{\overline{0}}$ of disease is different from that causing the pri- $\frac{\bar{P}}{\vec{D}}$ mary infection, and that this difference could not $\stackrel{\mathbb{\Omega}}{\Omega}$ have arisen by modification of the original organ- $\infty$ ism. Thus a difference may be shown either in the $\vec{\circ}$ pattern of drug sensitivity and resistance or, more recently, in bacteriophage type.

The use of drug resistance as a marker for the $\stackrel{\mathscr{\omega}}{\rightleftharpoons}$ tubercle bacillus was suggested by Thomas ${ }^{5}$ who $\vec{x}$ reported several cases with organisms resistant to drugs that the patient had never received, and in some of whom the history of tuberculosis extended I to prechemotherapy years, thereby suggesting 0

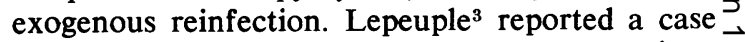
where the drug sensitivity pattern of organisms isolated from the maxillary sinus was completely different from that of the initial pulmonary disease. Contact with a case of similar sensitivity pattern $₹$ showing multiple drug resistances was shown, prov- $\vec{\oplus}$ ing exogenous reinfection. Similarly, in the case $\stackrel{0}{\circ}$ reported by Raleigh and Wichelhausen ${ }^{4}$ the third episode of clinical tuberculosis yielded organisms? with a different drug sensitivity pattern. In this latter case organisms were also of a different phage type, and it was therefore suggested that phage $\stackrel{\odot}{\varnothing}$ typing might provide another useful marker to $\overrightarrow{\vec{P}}$ help establish reinfection. It has since become $\frac{3}{3}$ clear that recovery of different phage types of $\frac{\partial}{\partial}$ tubercle bacilli from the same patient, either concurrently or consecutively, is not rare, but it is by no means certain that this necessarily indicates exogenous reinfection. ${ }^{6-9}$ Accordingly, while phage type is certainly a stable characteristic, ${ }^{10} \div$ it is less reliable than drug resistance pattern 3 . in definitely distinguishing reinfection from reactivation.

In our cases we consider that the time sequenceo of clinical and radiological events, together with the serial drug sensitivity patterns, established re-을 infection beyond any reasonable doubt. The mother's bacilli, resistant to isoniazid by 1975 , had $\%$ reverted to a mixture of sensitive and resistant 0 organisms during the last year of her life. The N bacilli recovered from the sons in mid-1978 were fully sensitive to isoniazid. This, the only difference in drug resistance pattern between the relapses in the sons and the source of reinfection, $\stackrel{\infty}{+}$ their mother, is thought to indicate reversion to 0 isoniazid sensitivity in the absence of the drug. The mother was chronically smear-positive during her last year of life, and both sons were shown tod be immunocompetent to tuberculin. Hence re- $\frac{\Omega}{\sigma}$ infection in the sons arose purely as a result of heavy exposure. 
These cases support the view expressed by Romeyn ${ }^{2}$ that under conditions of high environmental infectivity some relapses in tuberculosis are caused by exogenous reinfection.

\section{References}

1 Stead WW. Pathogenesis of a first episode of chronic pulmonary tuberculosis in man: recrudescence of residuals of the primary infection or exogenous reinfection. Am Rev Respir Dis 1967; 95:729-45.

2 Romeyn JA. Exogenous reinfection in tuberculosis. Am Rev Respir Dis 1970; 101:923-7.

3 Lepeuple A, Thibier R, Vivien JN, Grosset J, Canetti $B$. Un cas de transmission de bacilles de Koch d'un sujet tuberculeux a un sujet guéri de tuberculose pulmonaire. Rev Tuberc 1960; 24: 1312-21.

4 Raleigh JW, Wichelhausen R. Exogenous reinfection with Mycobacterium tuberculosis confirmed by phage typing. Am Rev Resp:r Dis 1973; 108:639-42.
5 Thomas OF, Borthwick WM, Horne NW, Crofton JW. Infection with drug-resistant tubercle bacilli. Lancet 1954; 1:1308-10.

6 Mankiewicz E, Liivak M. Phage types of Mycobacterium tuberculosis in cultures isolated from Eskimo patients. Am Rev Respir Dis 1975; 111: 307-12.

7 Bates JH, Stead WW, Rado TA. Phage type of tubercle bacilli isolated from patients with two or more sites of organ involvement. Am Rev Resp:r Dis 1976; 114:353-8.

8 Mitchison DA. Evidence for infection by two distinct strains of Mycobacterium tuberculosis in pulmonary tuberculosis. Am Rev Respir Dis 1976; 113:571.

9 Raleigh JW, Wichelhausen RH, Rado TA, Bates $\mathrm{JH}$. Evidence for infection by two distinct strains of Mycobacterium tuberculosis in pulmonary tuberculosis: report of nine cases. Am Rev Respir Dis 1975; 112:497-503.

10 Clavel S, Clement F. Stability of bacteriophage type of Mycobacterium tuberculosis: absence of variation caused by experimental chemotherapy in mice and analysis of spontaneous variation. Am Rev Respir Dis 1977; 115:433-7.

\section{European Conference on Sarcoidosis}

A European Conference on Sarcoidosis will be held in Novi Sad, Yugoslavia, from 22 to 24 May 1980. Further details may be obtained from Professor Stevan Goldman, Institut za Plućne Bolesti i Tuberkulozu, Sremska Kamenica, 21204 Sremska Kamenica, Yugoslavia, or Dr D Geraint James, Royal Northern Hospital, Holloway Road, London N7 6LD. 